\title{
Conversion disorder: the modern hysteria
}

\author{
Colm Owens \& Simon Dein
}

Abstract Conversion disorders tend to be poorly understood and diagnosis can be difficult. In this article, we aim to clarify what conversion disorders are and how they can be distinguished from other psychiatric disorders that involve physical symptoms. Prevalence, prognosis and relationship to organic disease are controversial areas; we outline what is known about them and provide some historical context. Aetiological theories and management strategies are discussed, the latter with the aid of case vignettes.

All doctors have encountered patients whose symptoms they cannot explain. These individuals frequently provoke despair and disillusionment. Many doctors make a link between inexplicable physical symptoms and assumed psychiatric illness. An array of adjectives in medicine apply to symptoms without established organic basis -'supratentorial', 'psychosomatic', 'functional' - and these are sometimes used without reference to their real meaning. In psychiatry, such symptoms fall under the umbrella of the somatoform disorders, which includes a broad range of diagnoses. Conversion disorder is just one of these. Its meaning is not always well understood and it is often confused with somatisation disorder. ${ }^{+}$Our aim here is to clarify the notion of a conversion disorder (and the differences between conversion and other somatoform disorders) and to discuss prevalence, aetiology, management and prognosis.

\section{What is a conversion disorder and how is it classified?}

The diagnosis of conversion disorder has always been controversial. In DSM-IV (American Psychiatric Association, 1994) it is categorised as a somatoform disorder (445), along with somatisation disorder, hypochondriasis, body dysmorphic disorder and pain disorder. Confusingly, in ICD-10 (World Health

+Somatisation disorders were discussed in the previous issue of APT: see Patel \& Sumathipala (2006) Psychological approaches to somatisation in developing countries. Advances in Psychiatric Treatment, 12, 54-62. Ed.
Table 1 Comparative categorisation of conversion disorder

\begin{tabular}{ll}
\hline DSM-IV category & ICD-10 approximation \\
Conversion disorder & $\begin{array}{r}\text { F44.4 } \begin{array}{l}\text { Dissociative motor } \\
\text { disorders }\end{array} \\
\text { F44.5 Dissociative convulsions } \\
\text { F44.6 Dissociative anaesthesia } \\
\text { and sensory loss }\end{array}$
\end{tabular}

Organization, 1992) conversion disorder falls under the category of dissociative (conversion) disorders (F44.-), alongside dissociative amnesia and fugue states (Table 1). In ICD-10, somatoform disorders fall into a different category entirely.

According to DSM-IV criteria (American Psychiatric Association, 1994: p. 457), conversion disorder is characterised by:

- one or more symptoms affecting voluntary motor or sensory function

- resemblance to neurological or medical disease

- involvement of psychological factors

- unintentional, unfeigned symptoms.

\section{Common symptomatology}

Table 2 lists the symptoms most commonly found in conversion disorder and Box 1 shows its differential diagnosis. The patterns of defects do not usually conform to recognised anatomical pathways, and symptoms may fluctuate and intensify when patients are aware that staff are observing them.

Colm Owens is a specialist registrar in old age psychiatry at Chase Farm Hospital (Enfield, Middlesex EN2 8JL, UK. E-mail: colm.owens@ beh-mht.nhs.uk.). Simon Dein is a senior lecturer in medical anthropology at University College London and honorary consultant neuropsychiatrist at Princess Alexandra Hospital, Harlow, Essex. Both authors have an interest in liaison psychiatry. Simon Dein has extensive experience of treating patients with conversion disorders and also has an interest in hypnotherapy. 


\begin{tabular}{ll} 
Table 2 Common symptoms of conversion disorder \\
\hline Sensory symptoms & Motor symptoms \\
Diplopia & Paralysis \\
Blindness & Dysphasia \\
Deafness & Ataxia \\
Numbness & Tremor \\
& Aphonia \\
& Seizures
\end{tabular}

\section{Historical background}

In the first edition of the DSM (now known as DSM-I) (American Psychiatric Association, 1952), conversion disorder appeared as 'conversion reaction' (Box 2). In DSM-II (1968), it was grouped with dissociation disorder under the new diagnostic category of 'hysterical neurosis', a title echoing the early concept of 'hysteria' resulting from uterine disorder in women (see 'Theories of conversion disorder' below). Subsequently, conversion disorder was conceptualised as a disorder of the brain associated with disordered emotions. The transition within the DSM to a system that classified psychiatric disorders by clinical phenomenology rather than aetiology resulted in the elimination of 'hysterical neurosis' from DSM-III (American Psychiatric Association, 1980) and its replacement by 'dissociation' disorders

\section{Box 1 Differential diagnosis of conversion disorder}

\section{Organic medical/neurological illness}

Somatisation Multiple,recurrentandfrequently changing physical symptoms over a lengthy period. Preoccupation with these symptoms, leading to marked distress in the patient: 'I've got all these pains, why can't they find out what's wrong with me?'

Hypochondriasis Preoccupation with having one (or more) serious physical illness, despite evidence to the contrary: 'I know I've got cancer, they just haven't done the right test yet'.

Factitious disorder Intentional feigning of symptoms with unclear motivation: the patient does not know why they are doing it. Also known as Munchhausen's syndrome.

Malingering Intentionalfeigning ofsymptoms with clear motivation: the patient does know why they are doing it.

\begin{tabular}{|c|c|c|}
\hline 1952 & DSM-I & Conversion reaction \\
\hline 1968 & DSM-II & $\begin{array}{l}\text { Hysterical neurosis } \\
\text { (conversion type) }\end{array}$ \\
\hline 1980 & DSM-III & Conversion disorder \\
\hline 1992 & ICD-10 & $\begin{array}{l}\text { Dissociative (conversion) } \\
\text { disorder }\end{array}$ \\
\hline 1994 & DSM-IV & Conversion disorder \\
\hline
\end{tabular}

and 'conversion' disorders. Conversion disorder was separated from dissociation disorder and categorised as a somatoform disorder. Thus, since 1980, the somatoform disorders and the dissociative disorders have been separate categories in the DSM. The characterisation of DSM somatoform disorders is by disturbances in physical sensations, or inability to move the limbs or walk, whereas DSM dissociative disorders involve involuntary disturbance in the sense of identity and memory.

Somatoform and dissociative disorders are now also separated in the ICD classificatory system but, as outlined above, conversion disorder falls under the category of dissociative disorders.

Conversion disorder is thought to occur primarily in societies with strict social systems that prevent individuals from directly expressing feelings and emotions towards others. Temporary somatic dysfunction is one possible mode of communication, particularly for those who are oppressed or underprivileged. The 'psychological mindedness' and ease of emotional expression typical of modern developed societies have led to the increasing rarity of conversion disorders in developed countries (Tseng, 2001).

\section{Prevalence}

Although many in the medical profession have formed the impression that the prevalence of conversion disorders in developed countries is in decline, there is little recent information. Much of the information we have about prevalence is derived from earlier studies, which often suggest that conversion symptoms are relatively common. Farley et al's (1968) findings in a study of 100 mothers of new born children suggested a lifetime prevalence of up to 33\%. Engl (1983) estimated that $25 \%$ of patients admitted to general medical services had had conversion symptoms at some time in their lives. Stephansson et al (1976) estimated the annual incidence to be about 22 cases per 100000 . 
Other studies suggest that the symptoms are most common in young women (Lazare,1981), rare in children under 8 years old (Perley \& Juze, 1962) and more common in rural areas, among uneducated people and in the lower socio-economic classes (Stephansson et al, 1976). The prevalence of these symptoms is generally felt to be higher among patients from minority ethnic groups. However, there is a lack of empirical data to support this assertion.

\section{Theories of conversion disorder}

Conversion has been attributed to many different mechanisms. One influential theory, dating back to Ancient Greek physicians who thought the symptoms specific to women, invoked as their cause the wandering of the uterus (hustera), from which the word hysteria derives. The term conversion was first used by Freud and Breuer to refer to the substitution of a somatic symptom for a repressed idea (Freud, 1894). This behaviour exemplifies the psychological concept of 'primary gain', i.e. psychological anxiety is converted into somatic symptomatology, which lessens the anxiety and gives rise la belle indifference, where a patient seems surprisingly unconcerned about their physical symptoms. The 'secondary gain' of such a reaction is the subsequent benefit that a patient may derive from being in the sick role.

As David \& Halligan (2000) point out, the concept of conversion disorder has raised great controversy between the proponents of psychological and physiological models of mental states. Conversion disorder raises the intriguing philosophical problem of how it is that psychological or mental states can effect long-term motor, sensory and cognitive changes in people claiming not to be consciously responsible for them. Theories falls into three main groups: psychoanalytic, learning theory and sociocultural formulations.

\section{Psychoanalytic theories}

Psychoanalytic explanations of conversion disorder emphasise unconscious drives, including sexuality, aggression or dependency, and the internalised prohibition against their expression (Hollander, 1980). A classic paradigm of this theory is the case of Anna O., who was treated by Freud (Breuer \& Freud, 1895). Physical symptoms allow for the expression of the forbidden wish or urge but also disguise it. Other psychoanalytic explanations focus on the need to suffer or identification with a lost object (Ford \& Folks 1985). An analytic therapist would attempt to treat a conversion disorder by helping the patient move to more mature defence mechanisms.

\section{Learning theory}

In a model that emphasises the shaping of behaviour by the environment, conversion symptoms are seen as maladaptive operant behaviours that act on the environment to produce reinforcing consequences (secondary gains). Conversion disorder is then sustained by the effects of these behaviours (McHugh \& Slavney, 1998: pp. 223-237). The therapeutic implications of this theory are that it is important to alter the patient's belief by means of countersuggestion and to take psychosocial measures to reduce the external benefits associated with the sick role. The aim of behavioural approaches is to ensure that the patient gains more from relinquishing symptoms than from maintaining them.

\section{The sociocultural hypothesis}

Sociocultural formulations of conversion disorder observe that in some cultures the direct expression of intense emotions is prohibited. As mentioned above, this may predispose people to exhibit conversion symptoms as a more acceptable form of communication. Conversion disorder would thus represent non-verbal communication of a forbidden idea or feelings. Such prohibitions can be reinforced by gender roles, religious beliefs and sociocultural influences (Schwartz et al, 2001). The expression of intense emotions in culturally defined rituals can be part of the healing process.

\section{Neurophysiology: the inhibition of willed movements}

There is evidence suggesting that conversion disorder is associated with impairment of cortical and subcortical functioning. Flor-Henri et al (1981) demonstrated impairment of both the dominant and non-dominant cerebral hemispheres in conversion disorder, the impairment being greatest in the former.

In an influential research project Vuilleumier et al (2001) studied seven people with unilateral hysterical sensorimotor loss in one arm. Positron emission computed tomography during passive vibratory stimulation of both hands showed low blood flow in two regions, the thalamus and the basal ganglia. In each individual, subcortical asymmetry involving contralateral basal ganglia and thalamic hypoactivation was present that resolved after recovery. It appears that voluntary commands were blocked from activating the pathways that controlled the paralysed arm. The results of this study suggest that hysterical conversion deficits are maintained by a functional disorder of striato-thalamo-cortical 
circuits controlling sensorimotor function and voluntary behaviour. The basal ganglia, specifically the caudate nucleus, might be particularly well suited to modulating motor processes based on emotional and situational information from the limbic system.

Marshall et al (1997) similarly reported on a woman with left-sided paralysis (without sensory loss) in whom no organic lesion could be found. They measured cerebral blood flow when she tried to move either her paralysed leg or her other leg. The attempt to move the paralysed leg failed to activate the right primary motor cortex. Instead there was activation of the right orbitofrontal and right anterior cingulate gyrus. This activity might have inhibited prefrontal (willed) effects on the right primary motor cortex when the woman attempted to move the paralysed leg.

These two studies suggest that inhibition of willed movement may play an important role in people with functional paralysis.

\section{Management}

It is crucial in any approach to patients with conversion disorder to establish a therapeutic alliance and to allow recovery with dignity and without loss of face. It is important that nursing and medical staff avoid labelling these individuals as manipulative, dependent or as exaggerating their difficulties.

\section{Explanation and psychotherapy}

Conversion symptoms, especially when acute, may undergo spontaneous resolution following explanation and suggestion. Some patients respond to active rehabilitation (Teasell \& Shapiro, 1994). Those with chronic and entrenched conversion symptoms may require admission to a psychiatric unit that has expertise in conversion disorder. Such individuals may undergo psychiatric decompensation as their symptoms improve, revealing depression or even previously hidden psychosis (Hurwitz \& Kosaka, 2001).

It may be helpful to explain to patients that sensorimotor disturbances can result from loss of conscious control over the affected function caused by a neurochemical disturbance, usually depression, thereby providing a cognitive framework for treatment. Cognitive-behavioural work should be combined with physiotherapy and any pharmacotherapy necessary for an underlying psychiatric disorder. Some clinicians offer abreaction to those with deeply entrenched symptoms. Many patients require family therapy, since families have often invested heavily in symptoms and have devoted considerable time and resources to helping their relative deal with their neurological difficulties.

\section{Hypnosis}

The similarities between hysteria, hypnosis and conversion disorder were noted during the 19th century. There is evidence that people with conversion disorder have above average levels of hypnotisability, making hypnosis a potential intervention in the management of the disorder (Van Dyck \& Hoogduin, 1989). The goals of such hypnosis include symptom reduction and exploration. Acting through the evocation of a trance-like state, which promotes suggestibility, hypnosis may be effective against symptoms that are influenced by suggestion. Hypnosis can also be used to evoke memories of a traumatic event that has a positive link with the symptoms.

Although there are many anecdotal accounts of the efficacy of hypnosis in conversion disorder, a recent randomised controlled trial of the addition of hypnosis to a comprehensive treatment programme for in-patients with the disorder found that it had no additional effect on treatment outcome (Moene et al, 2002).

\section{Prognosis}

Some 40 years ago Elliott Slater (1965) reported a 10-year follow-up study of patients admitted with conversion symptoms to the National Hospital for Nervous Diseases, London. He found that over half had developed clear-cut neurological or psychiatric conditions at follow-up. Since that time, several more follow-up studies have suggested an increased prevalence of neurological disorder in those with a diagnosis of hysteria or conversion disorder (Couprie et al, 1995; Mace \& Trimble, 1996). Others, however, have failed to show this relationship. Crimlisk et al (1998), for example, investigated the psychiatric and neurological morbidity, diagnostic stability and indicators of prognosis in patients identified 6 years previously as having medically unexplained motor symptoms. Unlike Slater, they found that a low level of physical and psychiatric diagnoses emerged to explain these individuals' symptoms or disability. Nevertheless, there was a high level of psychiatric comorbidity. Crimlisk et al also emphasised that reinvestigation of people with conversion disorder is expensive and can put them at unnecessary risk from complications associated with diagnostic procedures.

The discrepancy between the high rates of neurological disorders reported in some studies 
and the lower rates reported in others may arise from methodological issues, particularly problems with data analysis in the former group. Ron (2001), for example, points out how Slater's analysis is flawed and his conclusion, that hysteria is a 'delusion and a snare', highly misleading. The fact that Slater's findings continue to appear in medical textbooks perhaps reflects a prevailing fear among medical professionals about 'missing' an organic diagnosis.

Some conversion reactions are transient, whereas others are very persistent (Ford \& Folks, 1985). Chronic conversion can result in complications such as contractures. There is evidence that even chronic conversion symptoms can resolve spontaneously but resolution may be helped by insight-oriented, supportive or behavioural therapy (Lazare, 1981).

\section{Case vignette 1: Resolution by hypnosis}

A 24-year-old cleaner had an argument with his boss. Shortly afterwards he developed weakness of his right arm and an inability to talk. He was brought to an accident and emergency department. A full neurological examination, including a number of blood tests and a lumbar puncture, showed no specific abnormalities. His computed tomography (CT) and magnetic resonance imaging (MRI) scans were normal. His symptoms did not improve after a week in hospital. Finally, he was offered two sessions of hypnosis. His symptoms resolved completely at the end of the second session.

\section{Case vignette 2: Resolution by abreaction}

A 30-year-old African woman was the victim of an assault. She received a severe blow to her head and lost consciousness for about a minute. She subsequently developed weakness on the left side of her body, in both her arm and leg, and loss of vision in her left eye. She underwent thorough investigation at her local hospital, including a CT and MRI scan. Nothing abnormal was found. In several interviews with a psychiatrist she disclosed that she had been brought up unable to express anger. During a session of abreaction, she became very over-aroused and started screaming. Following this she slowly regained the use of her left arm and leg. It seemed apparent that her symptoms were the result of her inability to express anger.

\section{Conclusions}

Conversion disorder has received scant recent attention in the psychiatric literature compared with other psychiatric disorders. Although relatively uncommon today, general psychiatrists may be asked about its management. This is especially the case among those who work with patients from minority ethnic groups, in whom the prevalence of these disorders is felt to be higher. Further work is clearly required to examine prevalence in various patient groups and to study the efficacy of different modes of treatment for this disorder.

\section{References}

American Psychiatric Association (1952) Diagnostic and Statistical Manual of Mental Disorders. Washington, DC: APA.

American Psychiatric Association (1968) Diagnostic and Statistical Manual of Mental Disorders (2nd edn) (DSM-II). Washington, DC: APA.

American Psychiatric Association (1980) Diagnostic and Statistical Manual of Mental Disorders (3rd edn) (DSM-III). Washington, DC: APA.

American Psychiatric Association (1994) Diagnostic and Statistical Manual of Mental Disorders (4th edn) (DSM-IV). Washington, DC: APA.

Breuer, J. \& Freud, S. (1895) Studien über Hysterie. Reprinted (1957) as Studies on Hysteria (trans. and ed. J. Strachey). New York: Basic Books.

Couprie, W., Wijdicks, E. \& van Gijn Rooijmans, J. (1995) Outcome in conversion disorder: a follow up study. Journal of Neurology, Neurosurgery and Psychiatry, 58, 750-782.

Crimlisk, H. L., Bhatia, K., Cope, H., et al (1998) Slater revisited: 6-year follow-up study of patients with medically unexplained motor symptoms. $B M J, 316,582-586$.

David, A. \& Halligan, P. (2000) Cognitive neuropsychiatry: potential for progress. Journal of Neuropsychiatry and Clinical Neurosciences, 12, 506-510.

Engl, G. (1983) Conversion symptoms. In Signs and Symptoms: Applied Pathology, Physiology and Clinical Interpretation (6th edn) (ed. C. MacBryde). Philadelphia, PA: J. B. Lippincott.

Farley, J., Woodruff, R. A. Jnr \& Guze, S. B. (1968) The prevalence of hysteria and conversion symptoms. British Journal of Psychiatry, 114, 1121-1125.

Flor-Henri, P., Fromm-Auch, D. \& Tapper, M. (1981) A neurophysiological study of the stable syndrome of hysteria. Biological Psychiatry, 16, 601-626.

Ford, C. V. \& Folks, D. G. (1985) Conversion disorders: an overview. Psychosomatics, 26, 371-383.

Freud, S. (1894) The neuropsychosis of defence. Reprinted (1953-1974) in the Standard Edition of the Complete Psychological Works of Sigmund Freud (trans. and ed. J. Strachey), vol 3. London: Hogarth Press.

Hollander, M. (1980) The case of Anna O. A reformulation. American Journal of Psychiatry, 137, 797-800.

Hurwitz, T. \& Kosaka, B. (2001) Primary psychiatric disorders in patients with conversion. Journal of Depression and Anxiety, 4, 4-10.

Lazare, A. (1981) Current concepts in psychiatry: conversion symptoms. New England Journal of Medicine, 305, 745-748.

Mace, C. J. \& Trimble, M. R. (1996) Ten-year prognosis of conversion disorder. British Journal of Psychiatry, 169, 282-288.

Marshall, J., Halligan, P., Fink. G., et al (1997) The functional anatomy of a hysterical paralysis. Cognition, 64, B1-B8.

McHugh, P. R. \& Slavney, P. R. (1998) The Perspectives of Psychiatry (2nd edn). Baltimore, MD: John Hopkins University Press.

Moene, F., Spoinhoven, P., Hoogduin, K., et al (2002) A randomised controlled trial on the additional effect of hypnosis in a comprehensive treatment programme for in-patients with conversion disorder of the motor type. Psychotherapeutics and Psychosomatics, 71, 66-76.

Perley, M. \& Juze, S. (1962) Hysteria: the stability and usefulness of clinical criteria. A quantative study based on follow-up period of 6-8 years in 39 patients. New England Journal of Medicine, 266, 421-426.

Ron, M. (2001) The prognosis of hysteria/somatization disorder. In Contemporary Approaches to the Science of Hysteria: Clinical and Theoretical Perspectives (eds P. Halligan, C. Bass \& J. C. Marshall), pp. 271-281. Oxford: Oxford University Press.

Schwartz, A., Calhoun, A., Eschbich, C., et al (2001) Treatment of conversion disorder in an African American Christian woman: cultural and social considerations. American Journal of Psychiatry, 158, 1385-1391. 
Slater, E. (1965) Diagnosis of hysteria. BMJ, 1, 1395-1399.

Stephansson, J. G., Messina, J. A. \& Meyerowitz, S. (1976) Hysterical neurosis, conversion type: clinical and epidemiological considerations. Acta Psychiatrica Scandinavica, 53, $119-138$

Teasell, R. W. \& Shapiro, A. P. (1994) Strategic-behavioral intervention in the treatment of chronic nonorganic motor disorders. American Journal of Physical Medicine and Rehabilitation, 73, 44-50.

Tseng, W. (2001) Handbook of Cultural Psychiatry. San Diego, CA: Academic Press

Van Dyck, R. \& Hoogduin, K. (1989) Hypnosis and conversion disorders. American Journal of Psychotherapy, 43, 480-493.

Vuilleumier, P., Chicherio, C. \& Assal, F. (2001) Functional neuroanatomical correlates of hysterical sensorimotor loss. Brain, 124, 1077-1090.

World Health Organization (1992) The International Statistical Classification of Diseases and Related Health Problems, Tenth Revision (ICD-10). Geneva: WHO.

\section{MCQs}

1 In conversion disorder:

a symptoms may be intentionally produced

b there may be more than one physical symptom

c symptoms may involve the autonomic nervous system

d symptoms may not conform to specific dermatomes / myotomes

e organic pathology can readily be excluded.

2 Regarding the classification of conversion disorder:

a in DSM-IV, conversion disorder is in the same category as dissociative disorders

$\mathrm{b}$ in ICD-10, conversion disorder is in the same category as somatoform disorders

c in ICD-10, there is no single distinct entity of conversion disorder

d conversion disorder was previouly categorised as a hysterical neurosis

e classification is based on presumed aetiology.
3 In terms of prognosis:

a spontaneous recovery is rare

b chronicity may result in contractures

c there is a significantly increased prevalence of major neurological disorders

$\mathrm{d}$ there is evidence that rates of suicide are increased

e there may be underlying affective or psychotic illness.

4 The following have been used to treat conversion disorder:

a hypnosis

b abreaction

c antidepressants

d cognitive-behavioural therapy

e systemic family therapy.

5 As regards the prevalence of conversion disorder:

a prevalence in Western countries has increased over recent years

b they are well recognised in young children

c they are more common in men

d they are more common in less educated populations

e they are more common in lower socio-economic classes.

\begin{tabular}{|c|c|c|c|c|c|}
\hline \multicolumn{6}{|c|}{ MCQ answers } \\
\hline 1 & & 2 & 3 & 4 & 5 \\
\hline $\mathrm{a}$ & $\mathrm{F}$ & a $F$ & a $\mathrm{F}$ & a $\mathrm{T}$ & a $F$ \\
\hline$b$ & $\mathrm{~T}$ & b F & b $\mathrm{T}$ & $\mathrm{b} \mathrm{T}$ & $b \mathrm{~F}$ \\
\hline c & $\mathrm{F}$ & c $\mathrm{T}$ & c F & c $\mathrm{T}$ & c F \\
\hline d & $\mathrm{T}$ & d $\mathrm{T}$ & d F & d $\mathrm{T}$ & $\mathrm{d} \mathrm{T}$ \\
\hline e & $\mathrm{F}$ & e $F$ & e $\mathrm{T}$ & e $\mathrm{T}$ & e $\mathrm{T}$ \\
\hline
\end{tabular}

